\title{
Montelukast as add-on therapy with inhaled corticosteroids or inhaled corticosteroids and long- acting beta-2-agonists in the management of patients diagnosed with asthma and concurrent allergic rhinitis (the RADAR trial)
}

\author{
Paul K Keith MD MSc FRCPC ${ }^{1}$, Caroline Koch $\mathrm{PhD}^{2}$, Michel Djandji MD², Jacques Bouchard $\mathrm{MD}^{3}$, \\ Eliofotisti Psaradellis BSc ${ }^{5}$, John S Sampalis $\mathrm{PhD}^{4,5}, \mathrm{R}$ Robert Schellenberg MD ${ }^{6}, \mathrm{R}$ Andrew Mclvor $\mathrm{MD}^{1}$
}

\begin{abstract}
PK Keith, C Koch, M Djandji, et al. Montelukast as add-on therapy with inhaled corticosteroids or inhaled corticosteroids and longacting beta-2-agonists in the management of patients diagnosed with asthma and concurrent allergic rhinitis (The RADAR Trial). Can Respir J 2009;16(Suppl A):17A-24A.
\end{abstract}

OBJECTIVE: To evaluate the effectiveness of montelukast as add-on therapy for patients diagnosed with asthma and concurrent allergic rhinitis who remain uncontrolled while receiving inhaled corticosteroid (ICS) monotherapy or ICS/long-acting beta-2-agonist (LABA) therapy in a community practice setting.

DESIGN: An eight-week, multicentre, open-label, observational study. Patients were 15 years of age or older and, while treated with an ICS or ICS/LABA, had allergic rhinitis and uncontrolled asthma symptoms by at least two criteria as per the Canadian Asthma Consensus Guidelines. The primary outcome measure was the percentage of patients with controlled asthma symptoms after eight weeks of treatment with montelukast $10 \mathrm{mg}$ once daily added to ICS or ICS/LABA therapy.

RESULTS: In total, 1004 patients participated in the survey phase of the study. Of these patients, 319 continued in the treatment phase and 301 (94.4\%) completed the eight-week assessment. At baseline, all patients had uncontrolled asthma symptoms based on the Canadian Asthma Consensus Guidelines; at the eight-week assessment, 229 patients (76.1\%) achieved asthma control. According to the Asthma Control Questionnaire (as determined by scores of 0.75 or less), 164 patients (54.7\%) achieved well-controlled asthma at week 8 . The mean $( \pm \mathrm{SD})$ Asthma Control Questionnaire score decreased from $2.03 \pm 0.80$ to $0.92 \pm 0.80(\mathrm{P}<0.001)$ for all patients, representing a clinically significant improvement. A statistically and clinically significant reduction in the overall Mini Rhinitis Quality of Life Questionnaire score was achieved with a decrease from $2.57 \pm 1.20$ to $1.12 \pm 1.00(-1.45 \pm 1.35 ; \mathrm{P}<0.001)$. Patient and physician satisfaction rates with montelukast add-on therapy were also significantly increased when compared with baseline treatment.

CONCLUSION: Montelukast add-on therapy is effective for managing asthma and allergic rhinitis symptoms in patients who were previously uncontrolled with ICS or ICS/LABA treatment.

Key Words: Allergic rhinitis; Asthma; Inhaled corticosteroids; Long-acting beta-2-agonist; Montelukast
Ajout du montélukast aux corticostéroïdes en inhalation en monothérapie ou à l'association de corticostéroïdes en inhalation et de $\boldsymbol{\beta}_{2}$ agonistes à longue durée d'action dans la prise en charge des patients ayant reçu un diagnostic d'asthme et de rhinite allergique concomitante (étude RADAR)

OBJECTIF : Évaluer l'efficacité du montélukast comme traitement d'appoint dans la prise en charge extrahospitalière des patients ayant reçu un diagnostic d'asthme et de rhinite allergique concomitante, qui sont demeurés symptomatiques malgré le traitement avec des corticostérö̈des en inhalation (CSI) seuls ou une association de $\mathrm{CSI} / \beta_{2}$ agonistes à longue durée d'action (BALA).

PROTOCOLE : Étude multicentrique d'observation menée au su, d'une durée de huit semaines. Les participants, âgés de 15 ans et plus, présentaient une rhinite allergique et des symptômes d'asthme non maitrisés, déterminés par une réponse positive à au moins deux critères de maîtrise de l'asthme définis par la Conférence canadienne de consensus sur l'asthme, malgré un traitement avec des CSI en monothérapie ou une association CSI/BALA. Le principal paramètre d'évaluation était le pourcentage de patients présentant des symptômes d'asthme maîtrisés après huit semaines de traitement avec le montélukast à $10 \mathrm{mg}$ une fois par jour comme traitement d'appoint aux CSI ou aux CSI/BALA.

RÉSULTATS : Au total, 1004 patients ont participé à la phase de sondage de l'étude. De ces patients, 319 ont continué dans la phase de traitement et 301 (94,4 \%) ont complété l'évaluation de huit semaines. Au départ, tous les patients présentaient des symptômes d'asthme non maîtrisés selon la définition de la Conférence canadienne de consensus sur l'asthme; lors de l'évaluation à la semaine 8 , les symptômes de l'asthme étaient maîtrisés chez 229 patients (76,1\%). À la semaine 8, 164 patients (54,7\%) présentaient des symptômes d'asthme bien maitrisés selon le questionnaire ACQ (Asthma Control Questionnaire) (soit des scores de 0,75 ou moins). Le score moyen ( \pm É.T.) au questionnaire ACQ a diminué de 2,03 $\pm 0,80$ à 0,92 $\pm 0,80$ $(\mathrm{p}<0,001)$ pour tous les patients, ce qui constitue une amélioration significative sur le plan clinique. Une réduction significative sur les plans statistique et clinique a été notée quant au score obtenu sur le mini-questionnaire RQLQ (Rhinitis Quality of Life Questionnaire), avec une diminution de $2,57 \pm 1,20$ à $1,12 \pm 1,00(-1,45 \pm 1,35 ; \mathrm{p}<0,001)$. Par ailleurs, le degré de satisfaction des patients et des médecins à l'égard du traitement d'appoint avec le montélukast était significativement supérieur au degré de satisfaction rapporté avec les traitements initiaux.

CONCLUSION : Le traitement d'appoint avec le montélukast est efficace pour maîtriser les symptômes d'asthme et de rhinite allergique chez les patients qui demeurent symptomatiques malgré des CSI ou une association de CSI/BALA.

the prevalence of asthma in the general population is between $4 \%$ and $11 \%$ and the prevalence of rhinitis is between $10 \%$ and $30 \%$. Approximately $80 \%$ of the patients who suffer from asthma also have rhinitis (2-4). It has been observed that patients with asthma

E pidemiological studies have shown that asthma has increased in prevalence worldwide over the past decades, with varying rates throughout the world. Asthma is now estimated to affect approx mately 300 million people around the world (1). It is estimated that

ontreal; ${ }^{3}$ Université Laval, Quebec; ${ }^{4} \mathrm{McGill}$ University, Montreal

${ }^{1}$ McMaster University, Hamilton, Ontario; ${ }^{2}$ Merck Frosst Canada Ltd, Montreal; ${ }^{3}$ Université Laval, Quebec;
5JSS Medical Research, Montreal, Quebec; ${ }^{6}$ University of British Columbia, Vancouver, British Columbia

Correspondence: Dr PK Keith, McMaster University, 1200 Main Street West, 3V7-Health Sciences Centre, Hamilton, Ontario L8N 325.

Telephone 905-521-2100 ext 76374, fax 905-521-4971, e-mail keithp@mcmaster.ca 
and allergic rhinitis (AR) have higher rates of asthma exacerbations and increased emergency room visits compared with asthma patients without concurrent AR $(5,6)$. Therefore, patients with asthma and AR represent an important subgroup for clinicians because of the complexity of effectively managing the two associated conditions.

Asthma remains poorly controlled, even though a large number of patients are prescribed controller medications, mainly inhaled corticosteroids (ICS) (7). In general, asthma guidelines (8) suggest that ICS are the optimal initial therapy. This is supported by a recent trial (9) showing that the early use of low-dose ICS is associated with better control of symptoms but, most importantly, with a significant $44 \%$ reduction in severe exacerbations of asthma. Despite ICS treatment, an important proportion of asthma patients have uncontrolled symptoms. This lack of therapeutic effectiveness may be due to low efficacy of ICS monotherapy, low compliance and poor adherence to treatment regimens $(10,11)$. Other factors that may explain suboptimal asthma control include smoking (12), environmental conditions, inattentiveness to aggravating factors and interruption of therapy (13-15). According to treatment guidelines, ICS are considered to be first-line treatment in mild, uncontrolled asthma while leukotriene receptor antagonists may provide an alternative treatment for asthma patients who are not controlled, not satisfied or refuse to take ICS therapy (1618).

Montelukast is an orally administered, once-daily leukotriene receptor antagonist that may be used in the treatment of asthma. Recent studies have shown that for patients whose asthma is not controlled with ICS therapy, adding a second drug, rather than increasing the dose of ICS, results in improved control of symptoms (19-21).

The SingulaiR in Asthma anD Allergic Rhinitis (RADAR) study was a phase IV study with the aim to assess the effectiveness of montelukast add-on therapy to ICS or ICS and long-acting beta-2-agonist (LABA) treatment in patients with asthma and concurrent AR who were not controlled with their ICS treatment. Secondary objectives of the study were to assess the effectiveness of montelukast, change in quality of life and patient and physician global satisfaction. The study was conducted in the practices of community physicians across Canada.

\section{METHODS}

\section{Study design}

This was a phase IV, prospective, multicentre cohort study conducted on patients with asthma that were currently being treated with an ICS or ICS/LABA combination. The study was comprised of two distinct phases: a survey phase and a treatment phase. The aim of the survey phase was to describe the prevalence of AR, as well as the proportion of patients who had uncontrolled symptoms, or who were not satisfied or were nonadherent with ICS or ICS/ LABA treatment. The second or treatment phase of the study was conducted on the patients identified from the survey as having uncontrolled asthma symptoms. The maximum proportion of patients taking an ICS/LABA combination enrolled at each site was $50 \%$. The treatment phase of the study employed an openlabel, prospective, single-cohort design. Patients that were eligible and agreed to participate in the treatment phase of the study were treated with montelukast for eight weeks. Clinical assessments were conducted at baseline (week 0) and at eight weeks. All patients were required to sign the appropriate informed consent form before their participation in the study. Before each study visit, all patients were asked to refrain from using their short-acting beta-2-agonist (SABA) for $4 \mathrm{~h}$.

\section{Subject selection criteria}

For the survey phase of the study, eligible patients were 15 years of age or older (in Quebec, patients had to be 18 years of age or older) and had been diagnosed with asthma for at least six months. In addition to the criteria above, patients eligible for the treatment phase had to fulfill the following inclusion criteria: diagnosed with AR for at least one year; forced expiratory volume in $1 \mathrm{~s}$ of $80 \%$ or greater of the predicted value; user of an ICS or ICS/LABA at any dosage; and uncontrolled asthma defined as the presence of at least two of the criteria based on the Canadian Asthma Consensus Guidelines: daytime symptoms four days or more in the last week; night-time symptoms one night or more in the last week; mild infrequent exacerbations; absenteeism from school or work due to asthma in the last week; restricted physical activity in the last week; four doses or more of an SABA (apart from one dose/day before exercise) in the previous week; forced expiratory volume in $1 \mathrm{~s}$ or peak expiratory flow $90 \%$ or less of their personal best in the previous week; or diurnal variability in peak expiratory flow greater than $10 \%$ to $15 \%$ in the previous week.

Patients were excluded if their asthma symptoms were controlled or if they were being treated with montelukast or any of the following treatments at the time of entry into the study: an LABA alone, prednisone, regular use of theophylline, or other asthma medications such as sodium cromoglycate or nedocromil. Patients using an antibiotic for a respiratory tract infection at the time of entry into the study or treated with an antibiotic within 30 days for a respiratory tract infection (initiation of antibiotic treatment was permitted during the study) were also excluded. A history of chronic obstructive pulmonary disease, cystic fibrosis or immune deficiency requiring specific therapy or any other diseases that could influence the evolution of asthma were reasons for exclusion. Patients with a history of hypersensitivity to any component of montelukast were excluded. Patients diagnosed with rhinitis medicamentosa, patients with evidence of significant nasal obstruction due to structural causes that significantly interfere with nasal air flow, and patients unwilling to stop regular use of a histamine H1 antagonist for AR symptoms, or unwilling to stop use of antihistamine eye drops, cromoglycate eye drops or ophthalmic corticosteroids were also excluded from the study.

\section{Treatment and follow-up}

All patients were treated for eight weeks with $10 \mathrm{mg}$ montelukast sodium (Singulair, Merck \& Co Inc, USA) tablets taken once daily at bedtime. Patients were assessed by the treating physician at their clinic at baseline and eight weeks. All assessments, including respiratory function tests, were conducted according to the routine practice of the treating physicians.

\section{Outcome measures}

The primary effectiveness outcome measure was the proportion of patients for whom asthma symptom control was achieved after eight weeks of treatment with montelukast. Patients were considered to be uncontrolled for their asthma symptoms if two or more of the eight Canadian Asthma Consensus Guidelines criteria were met.

The secondary effectiveness outcome measures were the proportion of patients for whom asthma symptom control was achieved after eight weeks of treatment with montelukast, as defined by the Asthma Control Questionnaire (ACQ) score. The ACQ is a self-administered questionnaire that consists of seven seven-point Likert scale questions that describe the frequency and severity of asthma symptoms. The ACQ score is calculated as the mean of the seven items. The ACQ score ranges between 0 (wellcontrolled) and 6 (extremely poorly controlled); a score of 0.75 or 
greater (22) indicates uncontrolled symptoms. A decrease of 0.5 or more in the ACQ is considered to be a clinically significant improvement in symptom control. A secondary measure of effectiveness was the absolute and per cent change in the ACQ score between the baseline and the eight-week assessments.

Another secondary outcome measure was the change in the quality of life in patients with concurrent AR as assessed by the the Mini Rhinoconjunctivitis Quality of Life Questionnaire (MiniRQLQ). The MiniRQLQ was developed to measure the functional problems that are troublesome to adults with rhinoconjunctivitis. It is a self-administered questionnaire that has 14 questions in five domains (activity limitations, practical problems, nose symptoms, eye symptoms and other symptoms). The score ranges from 0 (least impairment) to 6 (greatest impairment possible); an average change in overall score of 0.7 or higher (23) is considered to be a clinically significant change in quality of life. The absolute and per cent changes in the five MiniRQLQ domains and the overall MiniRQLQ score were measured between baseline and the eight-week assessment. Patient and physician satisfaction with inhaled therapy and montelukast add-on therapy was also evaluated. Satisfaction with treatment was defined as reporting 'very satisfied' or 'satisfied' with controller medication. Dissatisfaction was defined as a report of being 'very dissatisfied' or 'dissatisfied' or 'neither satisfied or dissatisfied' with controller medication.

\section{Statistical methods}

Descriptive statistics were given for patient demographics, baseline characteristics, medical history and primary triggers for asthma exacerbation for the study sample as a whole. The asthma symptoms criteria and global satisfaction at the baseline and eight-week assessments were stratified by ICS or ICS/LABA drug group and were reported for the study sample as a whole. The secondary outcome measures, ACQ and MiniRQLQ scores, were stratified by ICS drug group and ICS dose categories. Patients were classified by ICS dose used at baseline into one of the following groups: low dose was defined as $250 \mu \mathrm{g} /$ day or less for fluticasone propionate or equivalent $(500 \mu \mathrm{g} /$ day or less for beclomethasone dipropionate and $1000 \mu \mathrm{g} /$ day or less for budesonide); moderate dose defined as greater than $250 \mu \mathrm{g} /$ day to $500 \mu \mathrm{g} /$ day for fluticasone propionate or equivalent (greater than $500 \mu \mathrm{g} /$ day up to $1000 \mu \mathrm{g} /$ day for beclomethasone dipropionate and greater than $1000 \mu \mathrm{g} /$ day up to $2000 \mu \mathrm{g} /$ day inclusive for budesonide); and high dose was defined as greater than $500 \mu \mathrm{g} /$ day for fluticasone propionate or equivalent (greater than $1000 \mu \mathrm{g} /$ day for beclomethasone dipropionate and greater than $2000 \mu \mathrm{g} /$ day for budesonide). Between-ICS drug group or ICS dose category comparisons for the above parameters were assessed for statistical significance with the $\chi^{2}$ test for categorical scales and the ANOVA for continuous scales.

Uncontrolled asthma control during the eight-week treatment period was calculated as the proportion of patients with two or more positive responses based on the asthma symptoms criteria as defined by the Canadian Asthma Consensus Guidelines. The proportion of patients with an ACQ score of 0.75 or less at eight weeks was also used as a secondary measure of effectiveness. The statistical significance of the mean and percent change in ACQ score within each patient group and the study sample as a whole was assessed for statistical significance with Student's $t$ test for paired samples. The statistical significance of between-group differences with respect to the changes in the ACQ and MiniRQLQ scores from baseline to eight weeks was assessed with one-way ANOVA. The statistical significance of the respective changes in asthma symptoms criteria and treatment satisfaction from baseline to week 8 was assessed using the McNemar-Bowker test for paired dichotomous data.
Missing data regarding the MiniRQLQ were handled using the MiniRQLQ background administration and analysis guidelines (23). If a patient did not report an answer to all 14 questions of the MiniRQLQ, the overall score was not computed. If, however, the answers to the specific domains were available, then a score for that specific domain was reported. Missing data in the ACQ questionnaires were handled using an optimal method as described by the ACQ background, administration and analysis guidelines $(24,25)$. To minimize the risk of bias, missing values were interpolated using either previous or subsequent completions of the questionnaire. There was only one patient for whom the ACQ score was not calculated at week 8 because none of the seven items from the questionnaire were answered.

In accordance with the real-life aim of the study, the intent-totreat principle was applied for the analysis of effectiveness. Therefore, all patients, including those with protocol violations, were included in the effectiveness analysis, provided that baseline and eight-week data were available. The analyses were performed using SPSS version 12.0 for Windows (SPSS Inc, USA).

\section{RESULTS}

\section{Patient disposition}

Patient enrolment began in April 2007; the last patient was enrolled in November 2007 and the last follow-up visit was completed in January 2008. A total of 1020 patients were enrolled by 72 physician investigators; 16 patients were excluded from the survey analysis due to protocol violations $(n=8,0.8 \%)$ and because no consent was provided $(n=8,0.8 \%)$. Of the 1004 patients included in the survey phase analysis, 319 eligible patients from 54 sites $(75.0 \%)$ accepted to participate in the treatment phase of the study. Of the 319 enrolled patients, 301 (94.4\%) completed the eight-week assessment. There were six patients that were screening failures and were excluded from the intent-to-treat analysis. During the treatment phase, 12 patients (3.8\%) discontinued before the eight-week follow-up visit. Reasons for discontinuation were: lost to follow-up $(n=9,2.8 \%)$, protocol violation $(n=1,0.3 \%)$ and withdrawal of consent $(n=2,0.6 \%)$. These 12 patients were not included in the effectiveness analysis because eight-week follow-up data were not available.

\section{Survey phase}

The demographics and characteristics of the 1004 patients who completed the survey phase of the study are described in Table 1. With respect to controller therapy, 414 patients $(41.2 \%)$ were on ICS, $434(22.4 \%)$ were on a combination inhaler (ICS/LABA), $103(10.3 \%)$ were on a leukotriene receptor agonist and $26(2.6 \%)$ were on a LABA. There were seven specific questions that assessed the asthma profile of the patients. The results showed that 518 patients $(51.6 \%)$ reported coughing, wheezing, breathing faster or a tight chest four or more times in the previous week (question 1). There were 405 patients $(40.3 \%)$ that reported being awakened due to asthma symptoms one or more times in the previous week (question 2). In addition, 381 patients (37.9\%) experienced a restriction in physical activities because of asthma in the previous week (question 3) and 214 patients (21.3\%) experienced an exacerbation in asthma symptoms in the previous three months (question 4 ). There were 87 patients $(8.7 \%$ ) that reported having missed work or school in the previous week because of asthma (question 5). Also, 383 patients (38.1\%) used the rescue inhaler four or more times in the previous week (question 6) and 207 (20.6\%) used extra inhalations of combination inhaler in the previous week (question 7 ). There were 728 patients $(72.5 \%)$ that reported at least one of the seven asthma symptoms above. From 
TABLE 1

Demographics and baseline characteristics

\begin{tabular}{|c|c|c|}
\hline Baseline characteristics & $\begin{array}{l}\text { Survey phase } \\
(n=1004)\end{array}$ & $\begin{array}{c}\text { Treatment } \\
\text { phase }(n=313)\end{array}$ \\
\hline Age, years & $47.6 \pm 17.3$ & $46.1 \pm 17.2$ \\
\hline \multicolumn{3}{|l|}{ Sex, n (\%) } \\
\hline Male & $364(36.3)$ & $114(36.4)$ \\
\hline Female & $640(63.7)$ & $199(63.6)$ \\
\hline Duration of asthma diagnosis, months & $162.3 \pm 147.6$ & $162.6 \pm 139.0$ \\
\hline $\begin{array}{l}\text { Duration of allergic rhinitis diagnosis, } \\
\text { months }\end{array}$ & - & $131.4 \pm 135.4$ \\
\hline \multicolumn{3}{|c|}{ Primary trigger for asthma exacerbation, $\mathrm{n}(\%)$} \\
\hline Viral infection & - & $89(28.4)$ \\
\hline Pet dander & - & $40(12.8)$ \\
\hline Dust mites & - & 35 (11.2) \\
\hline Weather conditions/humidity & - & $34(10.9)$ \\
\hline Pollen & - & $30(9.6)$ \\
\hline \multicolumn{3}{|l|}{ Smoking history, $\mathrm{n}(\%)$} \\
\hline Patient smokes & - & $56(17.9)$ \\
\hline Member of household smokes & - & $55(17.6)$ \\
\hline Patient quit smoking & - & $88(28.1)$ \\
\hline Member of household quit smoking & - & $44(14.1)$ \\
\hline \multicolumn{3}{|l|}{ Medical history, n (\%) } \\
\hline Allergic rhinitis & - & $313(100.0)$ \\
\hline Sinusitis & - & $91(29.1)$ \\
\hline Obesity & - & 107 (34.2) \\
\hline Eczema & - & $65(20.8)$ \\
\hline \multicolumn{3}{|l|}{ ICS drug group, n (\%) } \\
\hline Missing & - & $6(1.9)$ \\
\hline ICS only & - & $154(49.2)$ \\
\hline Fluticasone propionate & - & $103(32.9)$ \\
\hline Budesonide & - & $28(8.9)$ \\
\hline Beclomethasone dipropionate & - & $12(3.8)$ \\
\hline Ciclesonide & - & $11(3.5)$ \\
\hline ICS/LABA & - & $153(48.9)$ \\
\hline Budesonide + formoterol fumarate & - & $78(24.9)$ \\
\hline $\begin{array}{l}\text { Fluticasone propionate }+ \text { salmeterol } \\
\text { xinafoate }\end{array}$ & - & $74(23.6)$ \\
\hline Ciclesonide + formoterol fumarate & - & $1(0.3)$ \\
\hline
\end{tabular}

Data presented as mean $\pm S D$ unless otherwise specified. ICS Inhaled corticosteroid; LABA Long-acting beta-2-agonist

an AR questionnaire with 14 specific questions that evaluated the AR symptoms of the patients, there were 858 patients $(85.5 \%)$ that experienced at least one of the AR symptoms.

\section{Treatment phase}

Demographic data and baseline characteristics on patients included in the treatment phase of the analysis are described in Table 1. The most frequently used ICS therapy was fluticasone ( $n=103,32.9 \%$ ), followed by budesonide ( $n=28,8.9 \%)$. With respect to ICS/LABA use, the most frequently reported combination therapy was budesonide and formoterol fumarate $(n=78,24.9 \%)$, followed by fluticasone propionate and salmeterol xinafoate $(n=74,23.6 \%)$. There was missing ICS drug group information for six patients $(1.9 \%)$ in the study.

\section{Effectiveness outcome}

Table 2 describes the asthma control assessment stratified by ICS drug group at the baseline and eight-week assessments for all patients with concurrent AR, based on the Canadian Asthma Consensus Guidelines. There was missing information for one patient at baseline regarding the asthma control assessment; therefore, results were based on the 312 patients who completed this section of the questionnaire. At baseline, the most commonly reported symptom was "daytime asthma symptoms $\geq 4$ days in the last week" with 133 patients $(86.4 \%)$ in the ICS group and 128 patients $(83.7 \%)$ in the ICS/LABA group. For all eight

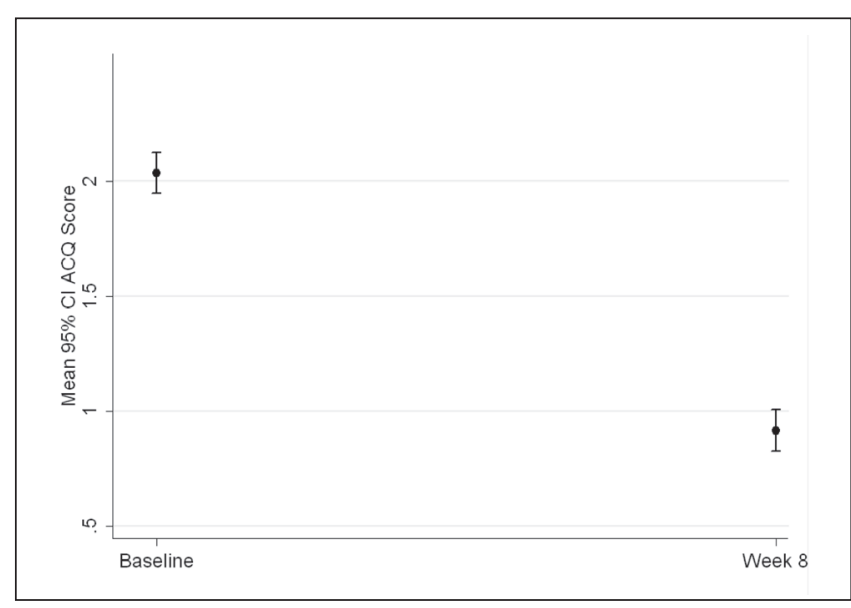

Figure 1) A statistically and clinically significant decrease from baseline to eight weeks in the mean ( $\pm 95 \% \mathrm{CI})$ Asthma Control Questionnaire (ACQ) score $(P<0.00)$

asthma symptom criteria, the changes in responses from the baseline to eight-week assessments were statistically significant (all $\mathrm{P}<0.015$ ) (Table 2). The between-group differences for ICS and ICS/ LABA group were similar for all asthma symptoms at baseline and the eight-week follow-up assessment. The only exception was "SABA use $\geq 4$ doses in the last week" with $112(72.7 \%)$ patients in the ICS group and $78(51.0 \%)$ patients in the ICS/LABA group $(\mathrm{P}<0.001)$. All 312 patients at baseline were uncontrolled as per the asthma control assessment definition at baseline. At week 8 , there were 72 patients $(23.9 \%)$ that were uncontrolled; 40 patients $(26.5 \%)$ in the ICS group and 32 (21.9\%) in the ICS/LABA group.

\section{ACQ}

The proportion of patients who reached well-controlled asthma in the ICS group (defined as ACQ scores of 0.75 or less) at eight weeks in the ICS subgroups (low-, moderate- and high-dose ICS) was $65.5 \%, 44.0 \%$ and $42.9 \%$, respectively. This difference in proportion between the three dose groups who were uncontrolled at baseline as per Canadian Consensus Guidelines was statistically significant $(\mathrm{P}=0.029)$. For these patients, a statistically and clinically significant decrease from baseline to eight weeks in the mean $( \pm \mathrm{SD})$ ACQ score of $1.17 \pm 1.01$ was observed $(\mathrm{P}<0.001)$ (Figure 1$)$. The mean and per cent $( \pm \mathrm{SD})$ changes in the ACQ score, respectively, for patients treated with low-dose $(-1.18 \pm 1.01$, $-55.6 \% \pm 38.3 \%)$, moderate-dose $(-1.12 \pm 0.94,-40.6 \% \pm 98.4 \%)$ and high-dose ICS $(-1.28 \pm 1.29,-44.0 \% \pm 43.8 \%)$ were also clinically and statistically significant (Tables 3 and 4).

The proportion of ICS/LABA patients who reached wellcontrolled asthma (defined as ACQ scores of 0.75 or less) at eight weeks in each ICS subgroup (low-, moderate- and high-dose ICS) was $52.8 \%, 54.2 \%$ and $50.0 \%$, respectively $(\mathrm{P}=0.972)$. For these patients, a statistically and clinically significant decrease from baseline to eight weeks in the mean ACQ score of $-1.07 \pm 0.99$ was also observed $(\mathrm{P}<0.001)$. Similar results in the mean and per cent changes in ACQ score were reported compared with patients in the ICS group (Table 4). For all patients, a statistically and clinically significant reduction in the ACQ score was achieved, with a mean decrease of $-1.11 \pm 1.00$ (from $2.03 \pm 0.80$ to $0.92 \pm 0.80$ ) $(\mathrm{P}<0.001)$.

\section{MiniRQLQ}

The MiniRQLQ for both ICS drug groups exceeded an improvement (change from baseline) of 0.70 or greater for the overall score and each domain (Figure 2). Patients in the ICS group reported a 


\begin{tabular}{|c|c|c|c|c|c|c|c|c|}
\hline & \multicolumn{4}{|c|}{ Baseline } & \multicolumn{4}{|c|}{ Week 8} \\
\hline & \multicolumn{3}{|c|}{ ICS/LABA, } & \multirow[b]{2}{*}{ Total, $\mathrm{n}=312$} & \multicolumn{3}{|c|}{ ICS/LABA, } & \multirow[b]{2}{*}{ Total, $\mathrm{n}=301$} \\
\hline & ICS, $n=154$ & $n=153$ & $\mathbf{P}^{*}$ & & ICS, $n=151$ & $n=146$ & $\mathbf{P}^{*}$ & \\
\hline \multicolumn{9}{|l|}{ Presence of the following asthma symptoms, $n(\%)$} \\
\hline 1. Daytime symptoms $\geq 4$ days in the previous week & $133(86.4)$ & $128(83.7)$ & 0.527 & $265(84.9)$ & $36(23.8)$ & $29(19.9)$ & 0.483 & $65(21.6)$ \\
\hline 2. Night-time symptoms $\geq 1$ night in the previous week & $112(72.7)$ & $108(70.6)$ & 0.705 & $224(71.8)$ & $44(29.1)$ & $32(21.9)$ & 0.184 & $77(25.6)$ \\
\hline 3. Mild infrequent exacerbations ${ }^{\dagger}$ & $56(36.4)$ & $62(40.5)$ & 0.483 & $118(37.8)$ & $9(6.0)$ & $7(4.8)$ & 0.799 & $16(5.3)$ \\
\hline $\begin{array}{l}\text { 4. Absenteeism due to asthma (school or work) in the } \\
\text { previous week }\end{array}$ & $16(10.4)$ & $28(18.3)$ & 0.052 & $44(14.1)$ & $3(2.0)$ & $0(0.0)$ & 0.248 & $4(1.3)$ \\
\hline 5. Restricted physical activity in the previous week & $93(60.4)$ & $99(64.7)$ & 0.480 & $193(61.9)$ & $27(17.9)$ & $23(15.8)$ & 0.645 & $50(16.6)$ \\
\hline 6. $S A B A \geq 4$ doses in the previous week $^{\ddagger}$ & $112(72.7)$ & $78(51.0)$ & $<0.001$ & $191(61.2)$ & $26(17.2)$ & $21(14.4)$ & 0.528 & $47(15.6)$ \\
\hline $\begin{array}{l}\text { 7. } \mathrm{FEV}_{1} \text { or } \mathrm{PEF} \leq 90 \% \text { of their personal best in the } \\
\text { previous week }\end{array}$ & 39 (25.3) & $37(24.2)$ & 0.895 & $77(24.7)$ & $1(0.7)$ & $5(3.4)$ & 0.116 & $6(2.0)$ \\
\hline $\begin{array}{l}\text { 8. Diurnal variability in PEF }>10 \% \text { to } 15 \% \text { in the } \\
\text { previous week }\end{array}$ & $10(6.5)$ & $18(11.8)$ & 0.117 & $29(9.3)$ & $1(0.7)$ & $3(2.1)$ & 0.364 & $4(1.3)$ \\
\hline Patient is uncontrolled ${ }^{\S}$ & $154(100.0)$ & $153(100.0)$ & $\mathrm{NC}$ & $312(100.0)$ & $40(26.5)$ & $32(21.9)$ & 0.417 & $72(23.9)$ \\
\hline
\end{tabular}

${ }^{*}$ Based on the $\chi^{2}$ test; ${ }^{\dagger}$ One exacerbation in the previous 3 months requiring a doctor visit or oral prednisone or an emergency room visit; ${ }^{\ddagger}$ Excluding one dose/day before exercise; ' Uncontrolled was defined by having at least 2 positive responses of the criteria listed above. $P<0.001$ based on the McNemar test for change in asthma control assessment between baseline and week 8 for total, inhaled corticosteroid (ICS) and ICS/long-acting beta-2-agonist (LABA) drug group for all asthma symptoms. The only exceptions were for asthma symptom $4(P=0.004)$ and asthma symptom $8(P=0.012)$ in the ICS drug group. FEV ${ }_{1}$ Forced expiratory volume in $1 \mathrm{~s}$; NC Not calculable; PEF Peak expiratory flow; SABA Short-acting beta-2-agonist

TABLE 3

Asthma Control Questionnaire (ACQ) and Mini Rhinoconjunctivitis Quality of Life Questionnaire (MiniRQLQ) outcome assessments

\begin{tabular}{|c|c|c|c|c|c|c|c|c|}
\hline & \multicolumn{4}{|c|}{ ICS } & \multicolumn{4}{|c|}{ ICS/LABA } \\
\hline & $\begin{array}{c}\text { Low-dose, } \\
n=89\end{array}$ & $\begin{array}{c}\text { Moderate-dose, } \\
\quad n=50\end{array}$ & $\begin{array}{l}\text { High-dose, } \\
n=15\end{array}$ & $\mathrm{P}^{*}$ & Low-dose, $n=93$ & $\begin{array}{c}\text { Moderate-dose, } \\
\quad n=51\end{array}$ & High-dose, $n=9$ & $P^{*}$ \\
\hline \multicolumn{9}{|l|}{ Asthma symptoms, $\mathrm{n}(\%)$} \\
\hline Well controlled asthma at week 8 & $57(65.5)$ & $22(44.0)$ & $6(42.9)$ & 0.029 & $47(52.8)$ & $26(54.2)$ & $4(50.0)$ & 0.972 \\
\hline \multicolumn{9}{|l|}{ ACQ, mean (SD) } \\
\hline ACQ score at baseline & $1.93(0.79)$ & $2.10(0.79)$ & $2.41(0.89)$ & 0.084 & $2.06(0.78)$ & $2.03(0.74)$ & $2.00(1.14)$ & 0.947 \\
\hline \multicolumn{9}{|l|}{ MiniRQLQ, mean (SD) } \\
\hline Overall score at baseline & $2.44(1.21)$ & $2.57(1.10)$ & $2.58(1.26)$ & 0.805 & $2.63(1.28)$ & $2.79(1.09)$ & $2.26(1.54)$ & 0.470 \\
\hline Overall score at week 8 & $0.96(0.75)$ & $1.26(1.10)$ & $0.97(0.96)$ & 0.163 & $1.09(1.02)$ & $1.29(1.11)$ & $1.50(1.89)$ & 0.429 \\
\hline \multicolumn{9}{|l|}{ MiniRQLQ domains, mean (SD) } \\
\hline Activities at baseline & $2.46(1.32)$ & $2.59(1.32)$ & $2.82(1.08)$ & 0.571 & $2.66(1.39)$ & $2.48(1.28)$ & $2.52(1.51)$ & 0.759 \\
\hline Activities at week 8 & $0.94(0.83)$ & $1.17(1.38)$ & $1.07(1.27)$ & 0.504 & $0.98(0.99)$ & $1.05(1.16)$ & $1.83(2.11)$ & 0.125 \\
\hline Nose symptoms at week 8 & $1.03(0.94)$ & $1.56(1.37)$ & $1.00(1.31)$ & 0.026 & $1.19(1.22)$ & $1.39(1.06)$ & $1.08(1.43)$ & 0.600 \\
\hline Eye symptoms at baseline & $2.04(1.55)$ & $2.04(1.38)$ & $2.24(1.85)$ & 0.888 & $2.14(1.59)$ & $2.58(1.52)$ & $2.37(2.04)$ & 0.296 \\
\hline Eye symptoms at week 8 & $0.80(0.92)$ & $0.89(1.00)$ & $0.76(1.11)$ & 0.834 & $1.03(1.21)$ & $1.30(1.39)$ & $1.46(2.19)$ & 0.442 \\
\hline Other symptoms at baseline & $2.25(1.55)$ & $2.55(1.70)$ & $2.42(1.70)$ & 0.566 & $2.55(1.55)$ & $2.80(1.50)$ & $1.89(1.89)$ & 0.250 \\
\hline Other symptoms at week 8 & $0.98(1.03)$ & $1.20(1.24)$ & $0.90(0.68)$ & 0.468 & $1.05(1.23)$ & $1.51(1.61)$ & $1.50(2.19)$ & 0.181 \\
\hline
\end{tabular}

*Based on ANOVA for continuous variables and $\chi^{2}$ for categorical variables. An ACQ score of $\leq 0.75$ was defined as 'well-controlled asthma'. ICS Inhaled corticosteroid; LABA Long-acting beta-2-agonist

mean decrease in overall MiniRQLQ score of $-1.45 \pm 1.35$; similar results were observed for the ICS/LABA group with a mean decrease of $-1.45 \pm 1.37$. With respect to the ICS drug groups stratified by ICS dose categories, all patients showed a significant reduction in the mean and per cent overall MiniRQLQ score and domains score. The only exception was patients that belonged to the high-dose ICS/LABA group for whom the decrease in scores did not reach statistical significance (Table 4). No betweengroup differences were reported for the change in MiniRQLQ. For the study sample as whole, a statistically and clinically significant reduction in the overall MiniRQLQ score was achieved, with a mean decrease of $-1.45 \pm 1.35$ (from $2.57 \pm 1.20$ to
$1.12 \pm 1.00)(\mathrm{P}<0.001)$. All MiniRQLQ domains showed a statistically significant reduction, with a mean decrease of $-1.53 \pm 1.51$ in the activities domain, $-1.67 \pm 1.74$ in the practical problems domain, $-1.67 \pm 1.56$ in the nose symptoms domain, $-1.20 \pm 1.65$ in the eye symptoms domain and $-1.35 \pm 1.53$ in the other symptoms domain. All changes were clinically and statistically significant $(\mathrm{P}<0.001)$.

Patient and physician satisfaction with treatment

Patients and investigators were asked to rate their level of satisfaction with controller therapy treatment at baseline and montelukast add-on therapy after eight weeks of treatment (Figure 3). At 
TABLE 4

Mean and per cent change in Asthma Control Questionnaire (ACQ) and Mini Rhinoconjunctivitis Quality of Life Questionnaire (MiniRQLQ) outcome assessments at eight weeks

\begin{tabular}{|c|c|c|c|c|c|c|c|c|}
\hline & \multicolumn{4}{|c|}{ ICS } & \multicolumn{4}{|c|}{ ICS/LABA } \\
\hline & Low dose & Moderate dose & High dose & $\mathrm{P}^{*}$ & Low dose & Moderate dose & High dose & $\mathrm{P}^{*}$ \\
\hline Mean change in ACQ score & $-1.18(1.01)$ & $-1.12(0.94)$ & $-1.28(1.29)$ & 0.871 & $-1.13(1.02)$ & $-1.01(0.93)$ & $-0.71(0.87)$ & 0.459 \\
\hline$P$ value within group & $<0.001$ & $<0.001$ & 0.003 & & $<0.001$ & $<0.001$ & 0.053 & \\
\hline Mean change in overall MiniRQLQ & $-1.50(1.39)$ & $-1.33(1.23)$ & $-1.57(1.60)$ & 0.750 & $-1.50(1.40)$ & $-1.46(1.29)$ & $-0.98(1.61)$ & 0.599 \\
\hline$P$ value within group & $<0.001$ & $<0.001$ & 0.003 & & $<0.001$ & $<0.001$ & 0.128 & \\
\hline \multicolumn{9}{|l|}{ Mean change in MiniRQLQ domains } \\
\hline Activities & $-1.54(1.52)$ & $-1.43(1.42)$ & $-1.79(1.41)$ & 0.716 & $-1.66(1.57)$ & $-1.40(1.58)$ & $-0.96(1.39)$ & 0.371 \\
\hline$P$ value within group & $<0.001$ & $<0.001$ & $<0.001$ & & $<0.001$ & $<0.001$ & 0.091 & \\
\hline Practical problems & $-1.61(1.74)$ & $-1.59(1.53)$ & $-1.82(2.03)$ & 0.898 & $-1.78(1.81)$ & $-1.71(1.72)$ & $-0.75(2.49)$ & 0.315 \\
\hline$P$ value within group & $<0.001$ & $<0.001$ & 0.005 & & $<0.001$ & $<0.001$ & 0.423 & \\
\hline Nose symptoms & $-1.81(1.55)$ & $-1.40(1.37)$ & $-1.43(1.64)$ & 0.263 & $-1.83(1.67)$ & $-1.57(1.53)$ & $-1.42(1.94)$ & 0.598 \\
\hline$P$ value within group & $<0.001$ & $<0.001$ & 0.006 & & $<0.001$ & $<0.001$ & 0.078 & \\
\hline Eye symptoms & $-1.27(1.72)$ & $-1.19(1.41)$ & $-1.43(1.95)$ & 0.882 & $-1.07(1.72)$ & $-1.23(1.58)$ & $-1.17(1.96)$ & 0.872 \\
\hline $\mathrm{P}$ value within group & $<0.001$ & $<0.001$ & 0.017 & & $<0.001$ & $<0.001$ & 0.136 & \\
\hline Other symptoms & $-1.28(1.39)$ & $-1.31(1.64)$ & $-1.45(1.85)$ & 0.922 & $-1.53(1.56)$ & $-1.33(1.58)$ & $-0.54(1.30)$ & 0.205 \\
\hline $\mathrm{P}$ value within group & $<0.001$ & $<0.001$ & 0.012 & & $<0.001$ & $<0.001$ & 0.276 & \\
\hline Per cent change in ACQ score & $-55.6(38.3)$ & $-40.6(98.4)$ & $-44.0(43.8)$ & 0.414 & $-49.9(44.1)$ & $-50.6(38.8)$ & $-47.9(51.6)$ & 0.987 \\
\hline$P$ value within group & $<0.001$ & 0.005 & 0.002 & & $<0.001$ & $<0.001$ & 0.034 & \\
\hline $\begin{array}{l}\text { Per cent change in overall } \\
\text { MiniRQLQ }\end{array}$ & $-49.6(46.3)$ & $-48.1(47.3)$ & $-53.5(44.1)$ & 0.929 & $-52.8(44.4)$ & $-51.5(36.5)$ & $-38.4(60.6)$ & 0.664 \\
\hline$P$ value within group & $<0.001$ & $<0.001$ & 0.001 & & $<0.001$ & $<0.001$ & 0.117 & \\
\hline \multicolumn{9}{|l|}{ Per cent change in MiniRQLQ domains } \\
\hline Activities & $-51.7(47.9)$ & $-50.8(69.1)$ & $-63.1(39.0)$ & 0.750 & $-55.9(47.0)$ & $-41.1(69.8)$ & $-44.9(55.6)$ & 0.332 \\
\hline$P$ value within group & $<0.001$ & $<0.001$ & $<0.001$ & & $<0.001$ & $<0.001$ & 0.057 & \\
\hline Practical problems & $-50.7(45.0)$ & $-41.3(55.5)$ & $-50.7(48.8)$ & 0.549 & $-39.5(101.8)$ & $-49.7(43.7)$ & $-15.8(90.9)$ & 0.553 \\
\hline$P$ value within group & $<0.001$ & $<0.001$ & 0.002 & & $<0.001$ & $<0.001$ & 0.637 & \\
\hline Nose symptoms & $-56.3(42.5)$ & $-46.3(46.1)$ & $-47.4(56.7)$ & 0.428 & $-53.3(46.6)$ & $-45.1(43.0)$ & $-36.7(62.0)$ & 0.445 \\
\hline$P$ value within group & $<0.001$ & $<0.001$ & 0.008 & & $<0.001$ & $<0.001$ & 0.138 & \\
\hline Eye symptoms & $-39.0(64.4)$ & $-42.1(63.1)$ & $-50.9(48.7)$ & 0.809 & $-28.3(98.7)$ & $-49.7(44.4)$ & $-35.0(77.8)$ & 0.384 \\
\hline $\mathrm{P}$ value within group & $<0.001$ & $<0.001$ & 0.003 & & 0.009 & $<0.001$ & 0.244 & \\
\hline Other symptoms & $-52.5(45.3)$ & $-40.4(72.6)$ & $-57.5(47.4)$ & 0.421 & $-54.5(53.2)$ & $-40.6(70.6)$ & $-27.1(52.8)$ & 0.257 \\
\hline$P$ value within group & $<0.001$ & $<0.001$ & 0.001 & & $<0.001$ & $<0.001$ & 0.190 & \\
\hline
\end{tabular}

*Based on ANOVA. Within-group P value is based on the one-sample T-test. ICS Inhaled corticosteroid; LABA Long-acting beta-2-agonist.

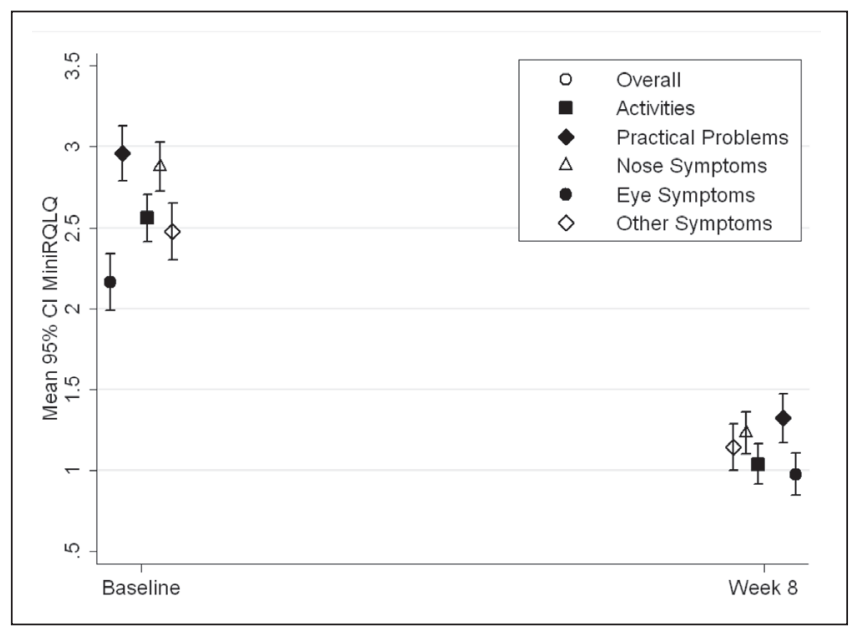

Figure 2) A statistically and clinically significant decrease from baseline to eight weeks in the mean $( \pm 95 \% \mathrm{CI})$ Mini Rhinoconjunctivitis Quality of Life Questionnaire (MiniRQLQ) scores $(P<0.001)$

the baseline assessment, for the ICS and ICS/LABA groups, 74.7\% and $60.8 \%$, respectively, of the patients were dissatisfied with their treatment and $25.3 \%$ and $39.2 \%$, respectively, were satisfied. At the eight-week assessment, for the ICS and ICS/LABA groups, $79.5 \%$ and $82.8 \%$, respectively, were satisfied with montelukast add-on therapy. Overall, there were $32.3 \%$ patients who were satisfied with their ICS therapy at baseline, and $81.7 \%$ were satisfied with their montelukast add-on therapy at week 8 . The change

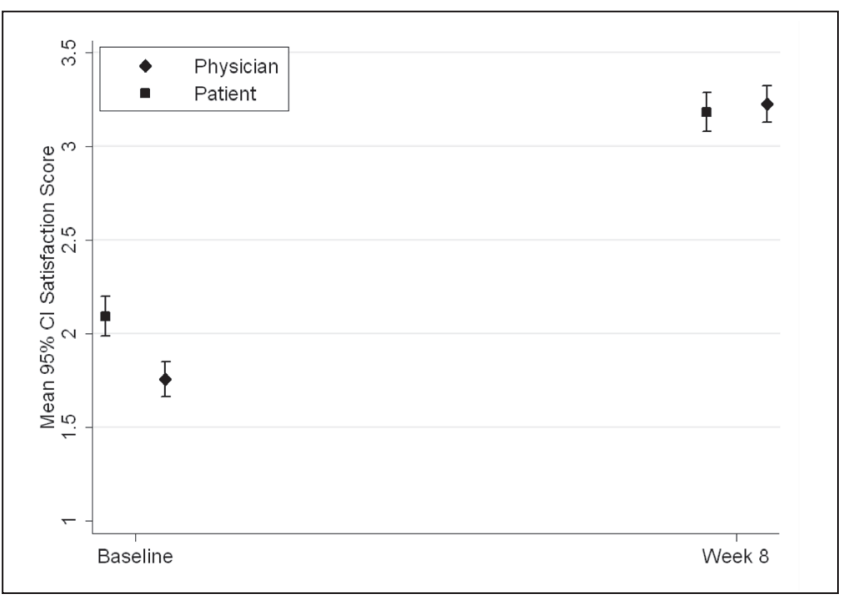

Figure 3) A statistically significant change from baseline to eight weeks in the mean $( \pm 95 \% \mathrm{CI})$ global satisfaction score for patients and physicians $(P<0.001)$

in patient satisfaction between the baseline and eight-week assessment was statistically significant $(\mathrm{P}<0.001)$. The investigator satisfaction with treatment results were similar to those obtained for patient satisfaction (Table 5).

\section{Safety}

Montelukast was well tolerated; there were no serious adverse events related to study drug reported over the course of the study. A total of 13 nonserious adverse events were reported by 11 


\begin{tabular}{|c|c|c|c|c|c|c|c|}
\hline & \multicolumn{3}{|c|}{ Baseline } & \multicolumn{3}{|c|}{ Week 8} & \multirow[b]{2}{*}{$\mathbf{P}^{*}$} \\
\hline & ICS & ICS/LABA & Total & ICS & ICS/LABA & Total & \\
\hline \multicolumn{8}{|c|}{ Patient global satisfaction with treatment, $\mathrm{n}(\%)$} \\
\hline Very satisfied & $8(5.2)$ & $15(9.8)$ & $24(7.7)$ & $64(42.4)$ & $70(47.9)$ & $136(45.2)$ & \\
\hline Satisfied & $31(20.1)$ & $45(29.4)$ & $77(24.6)$ & $56(37.1)$ & $51(34.9)$ & $110(36.5)$ & \\
\hline Neither satisfied nor dissatisfied & 49 (31.8) & $52(34.0)$ & $104(33.2)$ & $17(11.3)$ & $13(8.9)$ & $36(12.0)$ & $<0.001$ \\
\hline Dissatisfied & $60(39.0)$ & $36(23.5)$ & $97(31.0)$ & $14(9.3)$ & $11(7.5)$ & $16(5.3)$ & \\
\hline Very dissatisfied & $6(3.9)$ & $5(3.3)$ & $11(3.5)$ & $0(0.0)$ & $1(0.7)$ & $1(0.3)$ & \\
\hline Missing & $0(0.0)$ & $0(0.0)$ & $0(0.0)$ & $0(0.0)$ & $0(0.0)$ & $2(0.7)$ & \\
\hline Total, $\mathrm{n}$ & 154 & 153 & 313 & 151 & 146 & 301 & \\
\hline \multicolumn{8}{|c|}{ Investigator global satisfaction with treatment, n (\%) } \\
\hline Very satisfied & $3(1.9)$ & $4(2.6)$ & $7(2.2)$ & $69(45.7)$ & $65(44.5)$ & 135 (44.9) & \\
\hline Satisfied & 19 (12.3) & $34(22.2)$ & $54(17.3)$ & $51(33.8)$ & $58(39.7)$ & 110 (36.5) & \\
\hline Neither satisfied nor dissatisfied & $47(30.5)$ & $53(34.6)$ & $104(33.2)$ & $20(13.2)$ & $15(10.3)$ & $30(10.0)$ & $<0.001$ \\
\hline Dissatisfied & $84(54.5)$ & $57(37.3)$ & $142(45.4)$ & $9(6.0)$ & $7(4.8)$ & $25(8.3)$ & \\
\hline Very dissatisfied & $1(0.6)$ & $3(2.0)$ & $4(1.3)$ & $0(0.0)$ & $1(0.7)$ & $1(0.3)$ & \\
\hline Missing & $0(0.0)$ & $2(1.3)$ & $2(0.6)$ & $2(1.3)$ & $0(0.0)$ & $0(0.0)$ & \\
\hline
\end{tabular}

*Based on the McNemar-Bowker test for total and for the inhaled corticosteroid (ICS) and ICS/long-acting beta-2-agonist (LABA) groups

patients $(3.5 \%)$. The most frequently reported system organ class was for the respiratory, thoracic and mediastinal system $(n=4$, $1.3 \%)$ followed by the gastrointestinal system $(n=4,1.3 \%)$.

\section{DISCUSSION}

Patients who suffer from asthma also experience limitations in their physical, emotional, social and professional lives. The negative impact of asthma on a patient's life increases when asthma symptoms are not adequately controlled (26). According to the National Asthma Education and Prevention Program, the goals of asthma therapy are to achieve control of asthma symptoms by maintaining normal pulmonary function, preventing chronic symptoms and recurrent exacerbations, and providing optimal pharmacotherapy with minimal or no adverse events (17).

Because cysteinyl leukotrienes participate in the pathophysiology of both asthma and AR (27), it has been suggested that blocking the cysteinyl leukotriene receptor may be beneficial to patients with asthma and AR. Accordingly, recent studies have shown that montelukast can improve symptoms of seasonal AR and asthma in patients with both diseases $(28,29)$.

The survey determined that $85.5 \%$ of the patients with asthma also had one or more AR symptoms. Similar results were also found in other studies $(4,9)$ and confirm that AR is one of the most frequent concomitant symptoms of asthma.

In the current study, montelukast add-on therapy with ICS or ICS/LABA treatment was effective in achieving control and reducing asthma symptoms within eight weeks of treatment in patients who had uncontrolled asthma symptoms and AR. While all patients had uncontrolled symptoms - as defined by the Canadian Asthma Consensus Guidelines - at initiation of treatment, the vast majority had controlled symptoms after eight weeks of treatment with monteleukast. The results showed that montelukast was also effective in achieving asthma control, defined as an ACQ score of less than 0.75 . It should be noted that with the ACQ assessment there were $20(6.4 \%)$ patients that were controlled at baseline. Of these patients, 17 (85.0\%) maintained their asthma control, two patients $(10.0 \%)$ became uncontrolled and one patient $(5.0 \%)$ was lost to follow-up. A total of 164 patients $(54.7 \%)$ achieved asthma control at week 8 based on the ACQ.
Montelukast therapy was also effective in significantly reducing the ACQ score in patients treated with low-, moderate- and highdose ICS in the ICS and ICS/LABA groups. The only exception, with a nonstatistically significant decrease in ACQ score, was for the high-dose ICS/LABA group; however, this may be due to the low number of patients in this group.

The quality of life of patients with respect to their concomitant AR was significantly improved with montelukast add-on therapy. There were no significant between-group differences with respect to overall quality of life and specific domains. Therefore, regardless of whether patients were taking ICS monotherapy or ICS combination therapy in combination with montelukast, improvement in quality of life was observed. Both physician and patient satisfaction with montelukast combination therapy were also significantly increased compared with baseline ICS treatment.

Potential weaknesses of the present study include the singlecohort design without a parallel control group. The aim of the study, however, was to assess the effectiveness of montelukast in combination with ICS monotherapy or ICS/LABA therapy in patients who were not controlled with their current ICS therapy. Another potential weakness of the study is the open-label design. However, this is necessary for closer emulation of the real-life setting and routine clinical practice in which blinding of treatment used is not applicable. In addition, the study period was relatively short and long-term effects on asthma control, and especially asthma exacerbations, could not be reliably measured.

The strengths of the current study include the high potential for generalization of the study results to the Canadian target population; this was achieved by enrolling patients from a representative sample of Canadian general practitioners and family physicians. The use of standardized and validated questionnaires assessing the severity of asthma enhances the internal validity of the study and allows direct comparison of the results to those obtained in other clinical trials.

Overall, montelukast once daily was well-tolerated during the eight-week treatment period of the study. There were no treatmentrelated serious adverse events reported. Montelukast add-on therapy with ICS or ICS/LABA treatment is effective for managing asthma and AR symptoms in adult patients who were previously uncontrolled with ICS treatment. 
STUDY: Registered at < clinicaltrials.gov> Identifier NCT 00545844.

FUNDING: This study was funded by Merck Frosst Ltd.

ACKNOWLEDGEMENTS: Financial disclosures and potential conflicts of interest: C Koch is a former employee in Clinical Research at Merck Frosst Canada Ltd; J Sampalis is an employee of JSS Medical Research Inc (CRO). RA McIvor has received honoraria for continuing medical education (CME) and attending advisory board meetings for Abbott, AstraZeneca, Boehringer Ingelheim, GlaxoSmithKline, Merck Frosst, Novartis, Nycomed and Pfizer; PK Keith has received research support from Allergy Therapeutics, GlaxoSmithKline, Merck Frosst, Nycomed, and Schering. He has received honoraria for advisory boards/ lectures for AstraZeneca, GlaxoSmithKline, Merck, Novartis, Nycomed, and Schering; RR Schellenberg has received funds for CME, research and advisory boards from GlaxoSmithKline, Graceway, Merck Frosst, Novartis, Nycomed and Schering. J Bouchard has received support from AstraZeneca, Boehringer-Ingelheim, GlaxoSmithKline, Merck, Nycomed, Novartis and Schering. He has received honoraria for advisory boards/lectures/conferences for Astra-Zeneca, GlaxoSmithKline, Merck, Novartis, Nycomed and Schering. All investigators received grants related to the conduct of the study including but not limited to patient recruitment and case report form completion on a prorated basis. List of investigators: Arndt, Susanne; Bassett, Michael C; Clayton, Russell Pears; Du Preez, Miranda; Ezekiel, Daniel; Fera, Tharwat A; Hudon, Marck, Jussak-Kiellerman, Ewa M; Kelly, John L; Kiellerman, Andrew; Kooy, Jack; Kruger, Frederic J; Macdonald, John J; Nayar, Arun; Padayachee, Vinogaran; Simkus, Raymond; Achyuthan, Geeta; Marais, Cilliers; Morgan, David C; Ahluwalia, Rajpal; Ames, Robert; Barrs, Gary B; Bartlett, John; Belle-Isle, Jasmin; Bertrand, Carl; Biala, Barbara; Bobadilla-Martinez, Julio; Bodok-Nutzati, Rebecca; Bourkas, Angelo; Browne, Noel J; Bukovy, Brent; Bustin, Robin; Chaudhri, Arif; Che, Claudius; Coyle, Stephen J; Crocker, Percy; Dasilva, Terence; De Souza, Selwyn; Dhillon, Ripple; Dissanayake, Dilani; Dowell, Anthony; Dunkerley, Robert; Filipowicz, W Adam; Grossman, Steven; Habra, Magdi Y; Hamilton, Roger D; Hartford, Brian J; Henein, Sam; Hollands, Ralph; Hong, Tommy; Houde, Danielle; Hsin, Mabel; Jackman, Paul; Kalra, Bharat; Kim, James; Kotecha, Yatish J; Kozak, Joseph; Lotfallah, Talaat K; Lyttle, Brian; Mah, Douglas W; Rabb, Lucy; Kaplan, Alan; McGrath, Sheilagh; Mehta, Pravinsagar; Ng, Albert P; O’Mahony, William F; Pang, Patrick KK; Petrlich, Steve; Riche, Cyril; Russell, Alan; Sabry, Boshra; Luton, Robert; Schumacher, Albert J; Seaman, Donald Maxwell; Sochocka, Elzbieta; Murray, Jonathan; Sunerh, Pal; Tan-Wilson, H Ing; Tsang, Andy; Ubani, Nelson; William, Hany; Young, Michelle; Yu, Norman; Zaphiratos, Thomas; Rabb, Roderick; Henry, DG; Anand, Sanjiv; Barrière, Ginette; Breton, Jeannot; Charbonneau, Jacques; Chouinard, Guy; Dumais, Michelle; Gagnon, Robert; Gonzalez, Yolanda; Labbé, Mario; Lawless, John J; Payer, Pierre; Serfaty, Samuel; Sylvain-Lucien, Joseph M; Thériault, Lyne; Audet, Richard; Zackon, Harold M; Copeland, David Fraser.

\section{REFERENCES}

1. Masoli M, Fabian D, Holt S, Beasley R. The global burden of asthma: Executive summary of the GINA Dissemination Committee report. Allergy 2004;59:469-78.

2. Camargos PA, Rodrigues ME, Sole D, Scheinmann P. Asthma and allergic rhinitis as symptoms of the same disease: A paradigm under construction. J Pediatr (Rio J) 2002;78(Suppl 2):S123-8.

3. Leynaert B, Bousquet J, Neukirch C, Liard R, Neukirch F. Perennial rhinitis: An independent risk factor for asthma in nonatopic subjects: Results from the European Community Respiratory Health Survey. J Allergy Clin Immunol 1999;104:301-4.

4. Sibbald B, Rink E. Epidemiology of seasonal and perennial rhinitis: Clinical presentation and medical history. Thorax 1991;46:895-901.
5. Price D, Zhang Q, Kocevar VS, Yin DD, Thomas M. Effect of a concomitant diagnosis of allergic rhinitis on asthma-related health care use by adults. Clin Exp Allergy 2005;35:282-7.

6. Bousquet J, Gaugris S, Kocevar VS, et al. Increased risk of asthma attacks and emergency visits among asthma patients with allergic rhinitis: A subgroup analysis of the improving asthma control trial. Clin Exp Allergy 2005;35:723-7.

7. Cowie RL, Underwood MF, Mack S. The impact of asthma management guideline dissemination on the control of asthma in the community. Can Respir J 2001;8(Suppl A):41A-5A.

8. Bateman ED, Hurd SS, Barnes PJ, et al. Global strategy for asthma management and prevention: GINA executive summary. Eur Respir J 2008;31:143-78.

9. Pauwels RA, Pedersen S, Busse WW, et al. Early intervention with budesonide in mild persistent asthma: A randomised, double-blind trial. Lancet 2003;361:1071-6.

10. Cowie RL, Underwood MF, Field SK. Inhaled corticosteroid therapy does not control asthma. Can Respir J 2004;11:555-8.

11. Chapman KR, Ernst P, Grenville A, Dewland P, Zimmerman S. Control of asthma in Canada: Failure to achieve guideline targets. Can Respir J 2001;8(Suppl A):35A-40A.

12. Lazarus SC, Chinchilli VM, Rollings NJ, et al. Smoking affects response to inhaled corticosteroids or leukotriene receptor antagonists in asthma. Am J Respir Crit Care Med 2007;175:783-90.

13. Clark N, Jones P, Keller S, Vermeire P. Patient factors and compliance with asthma therapy. Respir Med 1999;93:856-62.

14. Cochrane MG, Bala MV, Downs KE, Mauskopf J, Ben-Joseph RH. Inhaled corticosteroids for asthma therapy: Patient compliance, devices, and inhalation technique. Chest 2000;117:542-50.

15. Haynes RB. Interventions for helping patients follow prescriptions for medications (Cochrane Review). The Cochrane Library 2003; (issue 3).

16. Global Strategy for Asthma Management and Prevention. Global Initiative for Asthma (GINA), 2006. <www ginasthma org> (Version current at 2006).

17. National Asthma Education and Prevention Program: Expert Panel Report: Guidelines for the diagnosis and management of asthma. Update on Selected Topics - 2002. J Allergy Clin Immunol 2002;110(Suppl 1):S141-219.

18. Malmstrom K, Rodriguez-Gomez G, Guerra J, et al. Oral montelukast, inhaled beclomethasone, and placebo for chronic asthma. A randomized, controlled trial. Montelukast/Beclomethasone Study Group. Ann Intern Med 1999;130:487-95.

19. Pauwels RA, Lofdahl CG, Postma DS, et al. Effect of inhaled formoterol and budesonide on exacerbations of asthma. Formoterol and Corticosteroids Establishing Therapy (FACET) International Study Group 2. N Engl J Med 1997;337:1405-11.

20. Greening AP, Ind PW, Northfield M, Shaw G. Added salmeterol versus higher-dose corticosteroid in asthma patients with symptoms on existing inhaled corticosteroid. Allen \& Hanburys Limited UK Study Group 1. Lancet 1994;344:219-24.

21. Bjermer L, Bisgaard H, Bousquet J, et al. Montelukast and fluticasone compared with salmeterol and fluticasone in protecting against asthma exacerbation in adults: One year, double blind, randomised, comparative trial. BMJ 2003;327:891.

22. Juniper EF, Bousquet J, Abetz L, Bateman ED. Identifying 'well-controlled' and 'not well-controlled' asthma using the Asthma Control Questionnaire. Respir Med 2006;100:616-21.

23. Juniper EF, Thompson AK, Ferrie PJ, Roberts JN. Development and validation of the Mini Rhinoconjunctivitis Quality of Life Questionnaire. Clin Exp Allergy 2000;30:132-40.

24. Juniper EF, O'Byrne PM, Guyatt GH, Ferrie PJ, King DR. Development and validation of a questionnaire to measure asthma control. Eur Respir J $1999 ; 14: 902-7$.

25. Juniper EF, O’Byrne PM, Roberts JN. Measuring asthma control in group studies: Do we need airway calibre and rescue beta2-agonist use? Respir Med 2001;95:319-23.

26. Braman SS. The global burden of asthma. Chest 2006;130(1 Suppl):4S-12S.

27. Dahlen S-E. Cysteinyl leukotrienes as common mediators of asthma and allergic disease. Clin Exp Allergy 2003;3:69-73.

28. Philip G, Nayak AS, Berger WE, et al. The effect of montelukast on rhinitis symptoms in patients with asthma and seasonal allergic rhinitis. Curr Med Res Opin 2004;20:1549-58.

29. Virchow JC, Bachert C. Efficacy and safety of montelukast in adults with asthma and allergic rhinitis. Respir Med 2006;100:1952-9. 


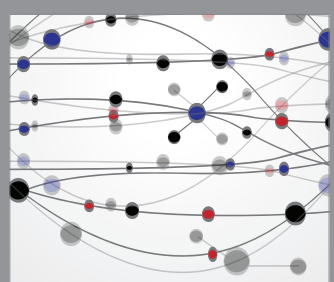

The Scientific World Journal
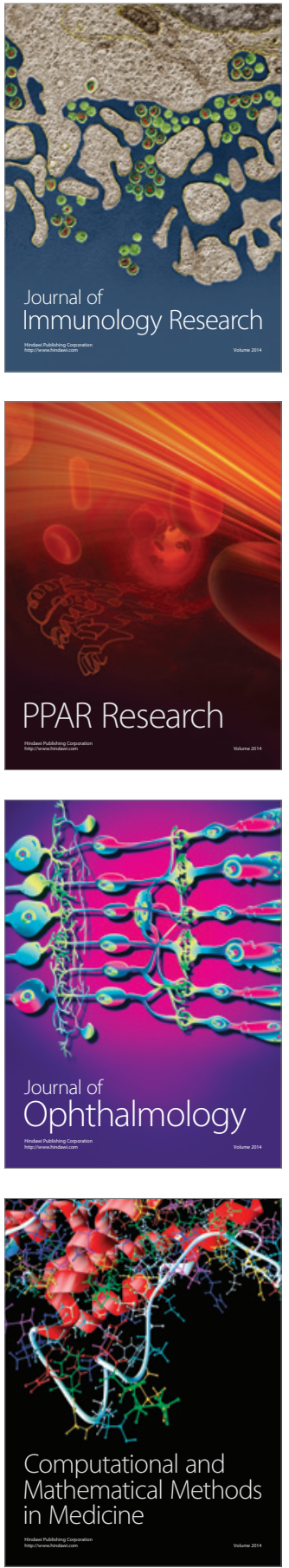

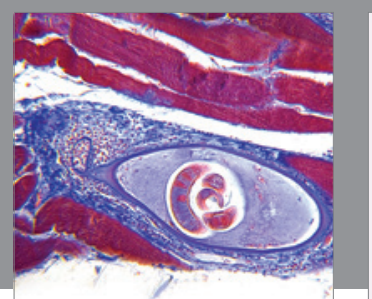

Gastroenterology Research and Practice

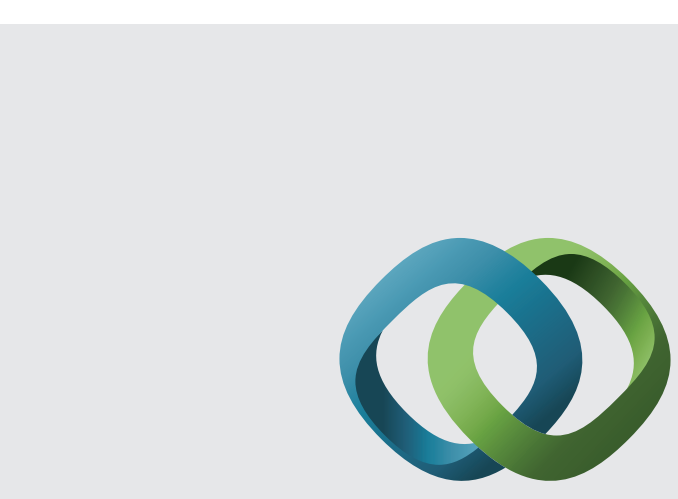

\section{Hindawi}

Submit your manuscripts at

http://www.hindawi.com
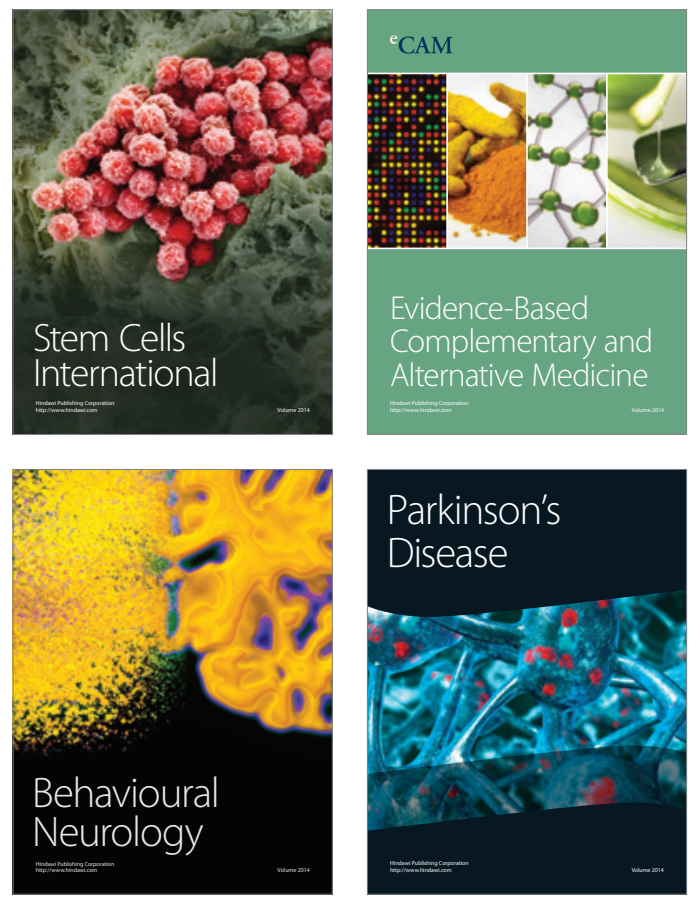
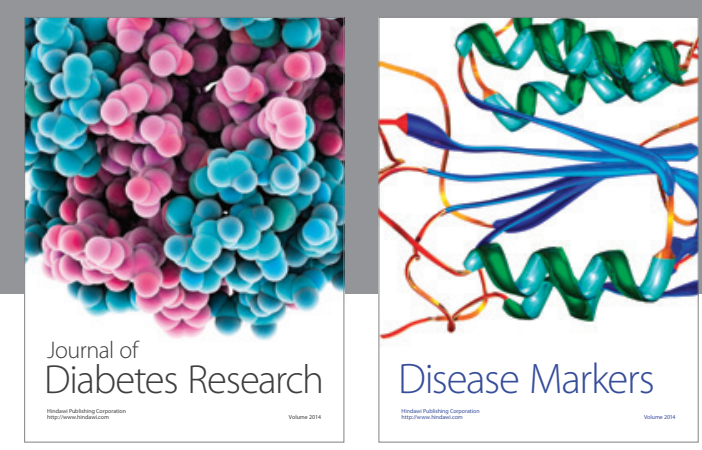

Disease Markers
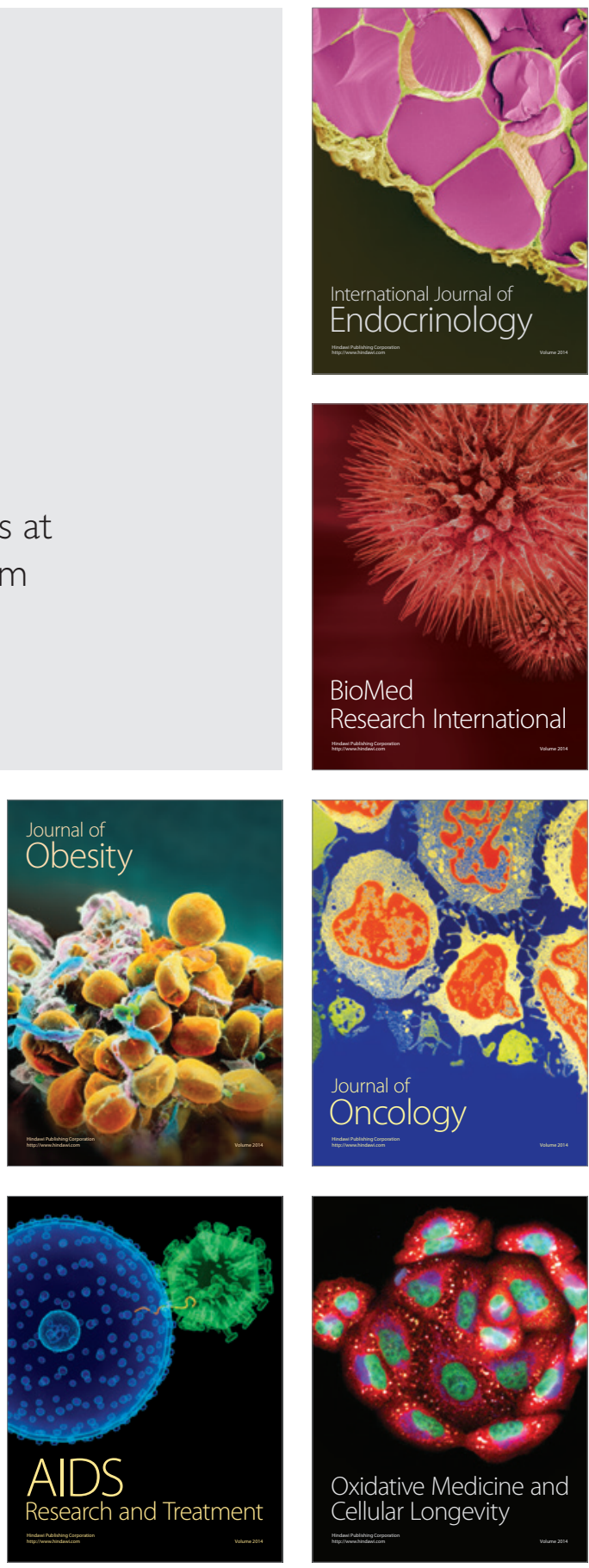